\title{
Percepção de colaboradores sobre as ações de treinamentos em uma indústria têxtil
}

\author{
Elizangela Maria Pas Menegon Mestre em Ciências Contábeis e Administração, UNOCHAPECÓ, Brasil - \\ elizangela.menegon@unochapeco.edu.br \\ Andrea Bencke Zambarda Mestre em Ciências Contábeis e Administração, UNOCHAPECÓ, Brasil - \\ zambarda@unochapeco.edu.br
}

\section{RESUMO}

A preparação dos colaboradores é um fator decisivo para a qualidade dos processos produtivos e dos produtos gerados por eles e consequentemente, para o sucesso das empresas do ramo têxtil, um constante desafio. 0 objetivo deste trabalho foi 0 de identificar a percepção de colaboradores, relativas a treinamentos, desenvolvidas pela educação corporativa, nas unidades produtivas de uma indústria têxtil localizada na região oeste catarinense. Trata-se de uma pesquisa descritiva com abordagem mista, pois trata os dados de maneira quantitativa e qualitativa, quanto aos procedimentos caracteriza-se como um estudo de caso. 0 estudo envolveu a totalidade dos colaboradores e supervisores das duas unidades produtivas que receberam o maior número de horas treinamento, configurando-se como censo e envolvendo 219 pessoas. Sobre os resultados, destaque para o estilo de gestão, com alinhamento entre os gestores de fábrica e a equipe de gestão de pessoas. A totalidade de colaboradores afirmam ter passado pelo processo de treinamento, $82,9 \%$ afirmam que os treinamentos ministrados atendem suas necessidades de aprendizado e desenvolvimento nas atividades e 92,6\% afirmam que os treinamentos recebidos ajudam a melhorar sua avaliação de desempenho e feedback. Os colaboradores também apontam que os treinamentos oferecidos pela empresa, proporcionam integração em suas áreas específicas de atuação. A junção de esforços relativos aos processos de educação corporativa vem sendo percebida pela maior parte dos colaboradores e demonstram alinhamento com a gestão estratégica. Destarte, é possível compreender a percepção dos colaboradores frente às ações, relativas a treinamentos, desenvolvidas pela educação corporativa da empresa.

Palavras-chave: Educação corporativa. Treinamentos. Gestão de pessoas.

\section{Perception of contributors on training actions in a textile industry}

\begin{abstract}
The preparation of the employees is a decisive factor for the quality of the productive processes and products generated by them and, consequently, for the success of the textile companies, a constant challenge. The objective of this research was to identify the perception of employees, related to training program developed by corporate education, in the productive units of a textile industry located in the western region of Santa Catarina. It is a descriptive research with a mixed approach, that treats the data in a quantitative and qualitative way. As for the procedures, it is characterized as a case study. The study involved all employees and supervisors of the two production units that received the most training hours, configured as a census and involving 219 people. Regarding the results, it highlighted the management style, with alignment between the factory managers and the people management team. The total number of employees report that they have gone through the training process, $82.9 \%$ affirm that the training programs provided meets their learning and development needs in the activities and $92.6 \%$ affirm that the training received helps to improve their evaluation of performance and feedback. The employees also point out that the training offered by the company provides integration in their specific areas of activity. The combination of efforts related to corporate education processes has been perceived by most employees and demonstrates alignment with strategic management. Thus, it was possible to verify the employees' perception of the actions related to the training programs developed by the corporate education of the company.
\end{abstract}

Keywords: Corporative education. Training programs. People management. 


\section{INTRODUÇÃO}

A qualificação da mão de obra é tida como um desafio para as empresas, principalmente para os novos colaboradores. Inseri-los adequadamente aos padrões, normas e cultura torna-se fator diferenciado quanto a sua integração ao time. Para as empresas, além dos investimentos tecnológicos, torna-se imprescindível o investimento no campo social, sendo a educação uma das áreas de atuaçaão efetiva. Rodrigues (1998) fala sobre a defasagem educacional da força de trabalho brasileira e como as empresas estão investindo recursos em áreas tradicionalmente de responsabilidade do Estado. A própria empresa cria suas escolas e universidades - as chamadas "Universidades Corporativas", para garantir uma educação sob medida (MEISTER, 1999; EBOLI, 2004). Santos $(2004$, p. 3) remete "o surgimento desse modelo de formação como a estratégia atualmente considerada a mais adequada pelo capital para a reprodução da força de trabalho".

As técnicas de aprendizagem são de significativa importância quanto à capacidade de adaptar e aprimorar sistemas e processos produtivos, na atual conjuntura isso passa a ser uma questão de sobrevivência. Como declara Meister (1999), as chances de uma organização mudar com sucesso dependem da capacidade dos trabalhadores de aprender novos papéis, processos e habilidades. Essa capacidade de ativar a inteligência, a inventividade e a energia do funcionário, surge à medida que o trabalho exige esforço cerebral, em detrimento do manual, corporal ou maquinal (MEISTER, 1999; DRUCKER, 1999; SVEIBY, 1998).

Nesse contexto, tem-se como problema de pesquisa: qual a efetividade das ações relativas a treinamentos desenvolvidas pela educação corporativa nas unidades produtivas de uma indústria têxtil?

Busca-se com esse trabalho levantar informações sobre a efetividade dos treinamentos, tendo em vista as ações de educação corporativa realizadas pela empresa, dessa forma, tem-se como objetivo identificar a efetividade das ações, relativas a treinamentos, desenvolvidas pela educação corporativa, nas unidades produtivas de uma indústria têxtil.

A presente pesquisa trata de um estudo de caso, realizado em uma indústria de confecções, localizada na região oeste de Santa Catarina. Caracteriza-se como descritiva com abordagem qualitativa e quantitativa. Quanto aos procedimentos, utilizou-se de pesquisa bibliográfica, documental, aplicação de questionários e entrevistas. Os dados quantitativos foram tabulados com o software Sphinx, a posteriori, realizada análise descritiva dos dados.

Após essa sessão introdutória será apresentada a revisão teórica com definições acerca do segmento têxtil, além da evolução e importância do setor, seguido da apresentação e análise dos dados, por fim, apresenta-se as considerações finais.

\section{REVISÃO DA LITERATURA}

Neste capítulo serão abordados temas referentes à gestão de pessoas, educação corporativa, assim como delimitado um panorama sobre o segmento da indústria têxtil.

\subsection{Gestão de Pessoas}

Gestão de pessoas destaca a complexidade das interações sociais que compõem o processo de gestão das organizações (BOSQUETTI, 2009).

Tachizawa, Ferreira e Fortuna (2006) descrevem a gestão de pessoas como sendo um processo sistêmico que inclui o planejamento, gestão e avaliação de pessoas, recrutamento, a seleção e a contratação dos colaboradores, além de ser responsável pelo treinamento e desenvolvimento da equipe, tem como atribuição manter um banco de profissionais, elaborar meios de recompensar e reconhecer os colaboradores com melhor desempenho e manter um bom clima organizacional.

O papel do setor de gestão de pessoas, antigamente delimitado aos recursos humanos, tomou projeção de consultoria interna, onde os profissionais técnicos necessitam acompanhar e apoiar as ações 
desenvolvidas por suas equipes, como também, elaborar estudos prospectivos alusivos à gestão da evolução do profissional em toda a empresa (TACHIZAWA; FERREIRA; FORTUNA, 2006).

Desse modo, a gestão de pessoas busca estar presente na estratégia da organização, sendo considerada área de apoio com uma peculiaridade que a distingue dos demais setores, pois não só trata da estratégia da empresa quanto ao envolvimento das pessoas para o ating imento dos objetivos organizacionais, mas trata da estratégia para 0 atendimento das suas próprias necessidades (ALMEIDA; TEIXEIRA; MARTINELLI, 1993).

As transformações observadas nas organizações vão além de novos nomes para antigas práticas. As mudanças práticas na gestão de pessoas apontam para um novo paradigma em relação aos recursos humanos nas empresas (BEER et al, 1985). As atividades que impactam o comportamento dos indivíduos e seus meios para executar as estratégias da empresa são definidas como gestão estratégica de pessoas (SCHULER, 1992).

Nos últimos anos, a administração de recursos humanos tem presenciado grandes mudanças em relação as temáticas de gestão de pessoas. Atualmente, as empresas associam práticas de recursos humanos com as estratégias organizacionais, no intuito de impulsionar o desempenho organizacional e a produtividade (RIBEIRO; MARTINS; NETAS, 2017). Dessa forma, ampliou-se a aceitação no que diz respeito a maneira pela qual as pessoas são geridas, sendo consideradas o fator mais importante em toda a matriz de competitividade (BARNEY; HERSTERLY, 2007).

Fleury e Fischer (1998), apresentam o aspecto estratégico, a cultura organizacional, os processos internos de atração e retenção, as ações relativas a qualidade de vida no trabalho e a gestão de competências como sendo as dimensões dos processos organizacionais relacionadas à gestão estratégica de pessoas.

Os meios tradicionais de sucesso de uma organização, como a tecnologia de produtos e processos, podem estabelecer vantagem competitiva, mas o essencial para a sustentabilidade do negócio é a disponibilidade de recursos humanos (RIBEIRO; MARTINS; NETAS, 2017). As pessoas que compõem uma organização são consideradas um dos mais importantes recursos das empresas (VERGARA, 2016). São os colaboradores, os responsáveis pelo sucesso e desempenho da empresa, é com base no seu trabalho que os objetivos e metas do negócio são atingidos.

Já Appelbaum et al (2000), exibem o conceito de gestão estratégica de pessoas como um conjunto de ações com intuito de melhorar a performance individual e organizacional. Esses autores apresentam a teoria AMO (Ability, Motivation, Opportunity) de desempenho, que aborda a influência positiva do gestor sob três perspectivas: habilidade (Ability), motivação (Motivation) e oportunidade (Opportunity). Segundo essa teoria, os colaboradores apresentam melhor desempenho quando têm habilidade em forma de conhecimento e capacitação para desenvolver o seu trabalho, são motivados quando adequadamente incentivados, ou seja, um real motivo Ihes é proposto para a ação e seu ambiente de trabalho oferece o suporte necessário no que diz respeito a oportunidade em demonstrar algo novo (BOSQUETTI, 2009).

Corroborando com Bosquetti (2009), Franco (2012) ressalta como diferencial das empresas a ênfase na formação, no desenvolvimento pessoal, profissional e no desempenho dos colaboradores, destaca ainda que as empresas modernas buscam com maior frequência os resultados por meio do desenvolvimento e formação das pessoas.

\subsection{Educação Corporativa}

A origem da educação corporativa é datada de 1955, nos Estados Unidos, quando empresas se tornaram líderes empresariais na economia global, e lançaram a educação corporativa com um meio para ganhar vantagem competitiva (MEISTER, 1999).

A educação corporativa tem por objetivo desencadear processos de aprendizagem com foco nas competências exigidas pela empresa (GARAVAN; O'CINNEIDE, 1994). A abordagem da educação corporativa é a contínua geração de conhecimento, a valorização do capital intelectual e a ênfase na aprendizagem organizacional (MEISTER, 1999; ALPERSTEDT, 2001).

O sistema de gestão de pessoas é responsável pelo alinhamento dos talentos humanos às estratégias da organização por meio da educação corporativa. Na concepção de organização que aprende e de gestão do 
capital intelectual, convergem-se as competências organizacionais, a missão e os valores da empresa (COLBARI, 2007). Para o mesmo autor, a qualificação profissional necessita inserir os colaboradores na cultura da organização, servir como forma de socializar os novos no início de suas atividades, além dos treinamentos relativos às questões técnicas, operacionais e logísticas, que são a essência de suas funções, dessa maneira, tem-se um perfil profissional flexível e inovador.

A educação corporativa é considerada como um trabalho em constante desenvolvimento, Meister (1999) a define como sendo "um guarda-chuva estratégico no desenvolvimento e na educação de colaboradores, clientes e fornecedores, no intuito de otimizar as estratégias organizacionais, além de proporcionar um laboratório de aprendizagem para a organização e um centro de educação permanente" (MEISTER, 1999, p. 8).

O conceito de educação corporativa surge no discurso empresarial como uma possibilidade de aprendizagem contínua, em uma tentativa de preencher lacunas deixadas pelo ensino tido como tradicional (QUARTIERO; BIANCHETTI, 2005). A partir desse modelo de formação, tem-se a estratégia mais adequada de reprodução da força de trabalho, assim, trabalho e aprendizagem andam lado a lado nas empresas (Santos, 2004).

Inicialmente, as áreas de treinamento e desenvolvimento eram formadas basicamente segundo a visão taylorista, com a separação entre a concepção do trabalho e sua execução (EBOLI, 2004). Destaca ainda, que a reprodução do conhecimento e a repetição da tarefa eram suficientes para um bom desempenho do trabalhador, com objetivo de desenvolver habilidades especificamente técnicas, a partir de demandas dos seto res da empresa. 0 foco das capacitações se limitava aos conhecimentos e habilidades necessárias ao cargo ocupado pelo funcionário, sem vínculo com as estratégias de negócio da empresa, ou seja, agregavam pouco valor ao resultado final. (RUAS, 2001; EBOLI, 2004).

Caon et al (2007) afirmam que treinamento é um processo de educação para aplicação do conhecimento em curto prazo e que utiliza metodologia e procedimentos planejados e organizados, nos quais os empregados, em geral, aprendem habilidades e conhecimentos técnico-específicos e bem definidos para um determinado trabalho ou atividade.

A atual conjuntura nos apresenta um novo paradigma, a concepção na conclusão de um curso formal está no aprender fazendo, no desenvolvimento da capacidade de aprender e dar continuidade nesse processo durante a execução do trabalho (MEISTER, 1999).

Há uma nova percepção sobre os treinamentos que engloba não só os participantes, mas principalmente a aprendizagem organizacional como um todo. As organizações estão repensando seus ambientes de aprendizagem, tornando-os proativos, centralizados, determinados e estratégicos (FIGUEIREDO, 2016).

O treinamento "prepara as pessoas para o desempenho do cargo mediante um processo continuo visando a manter permanentemente atualizadas com a tecnologia utilizada na realização de suas tarefas" (TACHIZAWA; FERREIRA; FORTUNA, 2006, p. 219).

A lógica do capitalismo vai além do saber operário, é necessário reter a disposição intelectual-afetiva para cooperar, trabalhar em equipe, visando a maior qualidade e produtividade. Nesse ínterim, o trabalhador é incentivado a pensar, a encontrar soluções antes que os problemas aconteçam (ALVES, 2000).

Eboli (2004), destaca que a migração do modelo tradicional de treinamento e desenvolvimento para a educação corporativa adquire foco e força estratégica e evidencia-se como um dos pilares de uma gestão organizacional de sucesso. "Essa ênfase na promoção de um espírito de aprendizado contínuo e permanente torna as universidades corporativas absolutamente diferentes das salas de aula corporativas e tradicionais no passado" (MEISTER, 1999, p. 28).

Ademais, Madruga (2018) destaca que as empresas devem evitar capacitações no formato de "adestramento", os treinamentos devem permitir que os aprendizes construam em conjunto o aprendizado, com a oferta de conteúdos inteligentes, tecnologias adequadas, instrutores experientes, além de oferecer ferramentas que favoreçam a aprendizagem, seja presencial, virtual ou mista, reforça que este é o verdadeiro compromisso da educação corporativa. 
Hoje em dia, as empresas estão criando suas escolas e universidades, chamadas de Universidades Corporativas (UC's), para garantir uma educação personalizada (MEISTER, 1999; EBOLI, 2004).

A Universidade Corporativa foi criada com intenção de aprofundar os treinamentos das empresas. No início era destinada a melhorar as habilidades técnicas dos colaboradores, após os anos 80 passou a opor as estruturas organizacionais rígidas, a consequência foi a mudança de foco para o desenvolvimento das capacidades individuais de forma contínua, de modo a manter útil e eficiente o seu capital intelectual (TARAPANOFF, 2006).

O surgimento das Universidades Corporativas tem como base o desafio de criar uma infraestrutura que garanta um processo de aprendizagem amplo, contínuo e permanente (FIGUEIREDO, 2016). Segundo o mesmo autor, com intuito de garantir seu lugar em um mercado altamente competitivo, as empresas estão investindo, cada vez mais, no setor de educação, e criando, assim, suas próprias Universidades Corporativas.

Para Eboli (1999), as empresas que adotam as UC's buscam um modelo de educação que prima o desenvolvimento de atitudes, posturas e habilidades, além dos conhecimentos técnicos. Ainda, a mesma autora, destaca que os melhores resultados são alcançados quando há parcerias com instituições de ensino superior que agregam valor com conhecimentos críticos ao negócio.

Como componentes fundamentais de uma UC, Meister citado por Carvalho (2001), destaca: a formação de um sistema de controle dos treinamentos, a criação de uma visão sobre o desenvolvimento dos colaboradores, a recomendação de capacitações para o alcance da estratégia junto com a obtenção de recursos, a criação de uma organização própria em treinamento e desenvolvimento, a identificação dos interessados (público interno e externo ao negócio), a criação de produtos e serviços específicos, a seleção de parceiros de aprendizagem, formatar o esboço de uma estratégia de tecnologia, a criação de um sistema de avaliação sobre a efetividade das ações e a comunicação para as partes interessadas.

As Universidades Corporativas garantem aprendizagem continuada pela interligação e criação do conhecimento com as inovações (ANDRADE; RODRIGUES, 2008). Fleury (2002) expõe a necessidade de práticas organizacionais que permitam as pessoas trabalharem cada vez mais e melhor, no intuito de unir a gestão do conhecimento na forma de educação corporativa.

Dentre os motivos que levam as empresas a investir na criação uma UC destacam-se, o desejo de vincular 0 aprendizado e 0 desenvolvimento às principais metas empresariais, com uma abordagem sistemática a estes; 0 desejo de difundir em toda a organização a cultura e os valores empresariais; e o desejo de desenvolver a empregabilidade dos funcionários (MEISTER, 1999).

Eboli (2004), salienta a missão da UC "em formar e desenvolver os talentos na gestão de negócios, promovendo a gestão do conhecimento organizacional (geração, assimilação, difusão e aplicação), por meio de um processo de aprendizagem ativa e contínua" (EBOLI, 2004, p. 48).

Com interesse de agregar valor e vantagem competitiva frente a seus concorrentes, as empresas utilizam-se das UC's para alcançar esse pressuposto, relacionando o aprendizado organizacional ao processo de mudança nas empresas (ULRICH; JICK; VON GLINOW, 1993). Garvin (2000), diz que uma organização que aprende é aquela preparada para criar, adquirir, interpretar, transformar e reter conhecimento e, a partir disso, modificar seu comportamento para refletir novos conhecimentos e insights. Tarapanoff (2006) defende a ideia que no longo prazo, a única e verdadeira fonte de vantagem competitiva das empresas será a capacidade de aprender antes dos concorrentes, e essa capacidade, nenhuma força externa poderá lhe tirar.

\subsection{Indústria têxtil}

A evolução da economia têxtil abriu novos caminhos para as cadeias de valor globais, alterando as estruturas de produção e consumo (GEREFFI; MEMEDOVIC, 2003). 0 mundo da produção têxtil mudou com a ascensão da China e de outros países asiáticos que iniciaram a disputa por preços e custos baixos (BRUNO, 2007).

Os negócios do setor se iniciam com a matéria-prima (fibras têxteis), sendo transformada em fios nas fábricas de fiação, de onde seguem para a tecelagem (que fabrica os tecidos planos) ou para a malharia (tecidos 
de malha). Posteriormente, passam pelo acabamento para finalmente atingir a confecção. "O produto final de cada uma dessas fases é a matéria-prima da fase seguinte". (COSTA; ROCHA, 2009, p. 162).

0 segmento têxtil, em nível mundial, é um dos mais dinâmicos. Exemplo disso são as várias coleções lançadas anualmente. A produção mundial de têxteis é liderada pela China, que detém $50,2 \%$ do montante produzido, além de representar o maior mercado consumidor no mundo (MENEGON; POLI; MAZZIONI, 2018). O Brasil ocupa o 5 o lugar na produção mundial de têxteis manufaturados, com 2,4\% do total (IEMI, 2013). Apesar da colocação do Brasil entre os cinco maiores fabricantes mundiais de produtos têxteis manufaturados, sua produção é voltada para atender basicamente ao mercado interno.

A Indústria Têxtil brasileira é concentrada na região Sudeste $(52,2 \%)$ e Sul $(28,3 \%)$. 0 Nordeste participa com $15,6 \%$, já o Centro-Oeste $(3,5 \%)$ e Norte $(0,4 \%)$ são considerados pouco representativos nessa atividade industrial (ASSOCIAÇÃO BRASILEIRA DA INDÚSTRIA TÊXTIL E DE CONFECÇÃO, 2015). Na década de 80 , a indústria têxtil brasileira dominava o mercado interno, este era fechado às importações de produtos acabados ou insumos e equipamentos. Em função disso, a cadeia produtiva baseia sua estratégia na melhoria de produtividade com a modernização do parque industrial e desenvolvimento de novos produtos, que ainda se encontram defasados em relação aos concorrentes mundiais (VIANA, 2005).

No Brasil, a indústria têxtil representa 2,0\% do Valor Bruto da Produção Industrial (VBPI) e conta com $3,8 \%$ dos empregos da Indústria de Transformação (IBGE, 2014). Em agosto de 2016, houve redução de 3,8\% da atividade industrial, queda mais intensa desde janeiro de 2012 (-4,9\%), onde a confecção de artigos do vestuário e acessórios teve resultado negativo 6,9\%. Ainda segundo dados do IBGE (2016), a comparação do mês de agosto 2016 com igual mês do ano anterior, o setor industrial mostrou queda de 5,2\%, entre as atividades, a de confecção de artigos do vestuário e acessórios, queda de 7,3\%.

Essa queda do desempenho industrial traz um alerta sobre o nível de competitividade e inovação do setor têxtil. A baixa produtividade das indústrias de confecção brasileiras, precisa atender às necessidades de um mercado crescente, e concorrer com grandes cadeias varejistas que, em sua maioria, atuam com a importação de produtos de revenda. Esse fato acaba levando à terceirização de processos com pequenas facções que tendem a compartilhar a produção com outras oficinas ainda menores e, em consequência, a qualidade do produto final é prejudicada.

Vianna (2005) traça um panorama da indústria têxtil brasileira, considerando como principais características a heterogeneidade tecnológica e gerencial. Em um mesmo segmento encontram-se empresas modernas, com padrão tecnológico e estratégias semelhantes às melhores empresas do mundo e, em contrapartida, encontram-se empresas parcialmente modernizadas, com alguns equipamentos atualizados em processos considerados estratégicos e contam com rigoroso controle de qualidade e capacitação em design. Porém, neste mesmo segmento, encontram-se várias empresas com pad rões tecnológicos e gerenciais ultrapassados.

0 estado de Santa Catarina destaca-se como um dos principais produtores do setor têxtil. Dados do ministério do trabalho e emprego (2012) apresentam o estado na segunda colocação do ranking nacional quanto a estabelecimentos de têxteis e confecções do país.

0 setor têxtil e de confecções é um dos mais dinâmicos da economia catarinense, prova disso é a liderança na geração de empregos no estado nos dois primeiros meses de 2017, sendo responsável por $26 \%$ dos postos de trabalho criados no período e por $21 \%$ do total de empregos nas indústrias catarinenses (FIESC, 2017).

Iniciativa entre IEL e Senai, intitulada Programa de Capacitação Empresarial para Pequenos Negócios, mostra a preocupação das entidades de classe do estado de Santa Catarina com a escolaridade e qualificação profissional, além da saúde e do bem-estar dos seus trabalhadores. Dados da FIESC (2017), sobre a execução do projeto apontam que desde 2015, já foram capacitadas 63 indústrias, com cursos em gestão de processos, gestão financeira, sucessão, governança, liderança e inovação.

A opção por estratégias voltadas para a criação de conhecimento e capacidade de produzir inovação, denota a adesão consciente das empresas do segmento têxtil a um sistema de valores que estabelece um patamar mínimo para a contribuição efetiva ao desenvolvimento pessoal e profissional dos colaboradores. 
Essa perspectiva de aprendizado e crescimento é vista como forma de organização da visão estratégica dos negócios (Kaplan; Norton, 2004).

\section{METODOLOGIA}

A presente pesquisa, foi realizada entre os meses de fevereiro a novembro de 2017 e apresenta informações tendo em vista as ações de educação corporativa realizadas pela empresa. Quanto aos objetivos, esta pesquisa caracteriza-se de natureza descritiva.

Dada a abordagem do problema, compreende-se como mista, tratando os dados de forma qualitativa e quantitativa, assumindo o perfil de um estudo de caso realizado em uma indústria têxtil localizada na região oeste catarinense. A população participante da pesquisa foi constituída pelos 96 (noventa e seis) colaboradores da unidade Centro de Abastecimento e 123 (cento e vinte e três) colaboradores da unidade Camisaria, e aos respectivos supervisores, por serem os que mais receberam treinamentos em 2017. 0 estudo envolveu a totalidade dos colaboradores e supervisores das duas unidades produtivas que receberam o maior número de horas treinamento, configurando-se como censo e envolvendo 219 pessoas.

A coleta de dados envolveu quatro momentos. Primeiramente, por meio da pesquisa documental, realizado levantamento de dados das horas de treinamento, principais temas trabalhados, horas de treinamentos por área da empresa e número de colaboradores, após deu-se a aplicação dos questionários aos colaboradores, os instrumentos utilizados para coleta dos dados foram disponibilizados aos colaboradores de forma impressa, entregue presencialmente a cada colaborador, no início do intervalo de almoço e recolhido, no mesmo dia, no retorno do intervalo, destes, retornaram e foram validados $52 \%$. 0 questionário foi composto por onze (11) questões, que versaram sobre os treinamentos oferecidos pela emp resa, as opções de respostas obedeceram a escala Likert, com extremos entre "concordo totalmente" e "discordo totalmente". Também deixada uma questão aberta para sugestões e/ou observações.

A terceira parte coube entrevistas semiestruturadas com os superviso res de cada unidade produtiva, que serão identificados como gestor A e gestor B, respectivamente. As entrevistas foram realizadas individualmente, na sala de reuniões da unidade Camisaria, no mesmo dia da aplicação da pesquisa junto aos colaboradores. 0 roteiro da entrevista versou sobre os treinamentos oferecidos, com vistas a proporcionar uma percepção mais afinada dos gestores, frente a participação de seus colaboradores, das ações de educação corporativa desenvolvidas pela empresa.

Ao final, realizou-se a tabulação dos dados e interpretação dos resultados, para isso, foram utilizados diferentes procedimentos, de acordo com a característica dos dados e informações coletadas. Os questionários foram tabulados usando o software Sphinx para tratamento das informações adquiridas e interpretação, sendo realizado encadeamento dos dados coletados com os conceitos apresentados no referencial teórico. De posse das informações, seguiu-se a análise descritiva dos dados, no intuito de relatar comportamentos sobre o objetivo da presente pesquisa, na população estudada (BEUREN, 2004). Com base nos resultados da pesquisa, foram apresentadas sugestões de melhoria ao programa de treinamento e desenvolvimento da empresa.

\section{APRESENTAÇÃO E ANÁLISE DOS DADOS}

Entre os dados levantados junto ao departamento de recursos humanos da indústria ora pesquisada, sobre o programa de treinamento oferecido aos colaboradores, destaque para o número de horas de treinamentos oferecidas em 2017, de janeiro a setembro, que foi de 5.293 horas, destas, a área de operações (produção) participou de $87 \%$ das horas de capacitação. As unidades caso estudadas, dão conta de que há efetividade dos treinamentos, pois estes atendem as demandas da empresa e, também, por se tratar das unidades que mais receberam capacitações no ano de 2017, em média, foram 2,65 horas/homem/treinamento por mês, de janeiro até setembro/2017.

No intuito de corroborar com a percepção dos colaboradores, foram relacionadas a análise das entrevistas dos gestores A e B, a fim de validar a efetividade dos treinamentos oferecidos. No primeiro item, os colaboradores foram questionad os se a empresa fornece treinamento de integração, 95,1\% dos colaboradores 
concordam plenamente e 4,9\% concordam que a empresa aplica treinamentos de integração aos novos colaboradores. A respeito desse questionamento, o gestor A diz que "a empresa sempre forneceu o treinamento de integração, que é um requisito mínimo para entrada de novos colaboradores na empresa". $O$ gestor B reforça a existência do treinamento de integração a todos os colaboradores entrantes, cita que "seria interessante que a cada dois, três anos a empresa refizesse o treinamento de integração aos colaboradores mais antigos [...] existem mudanças na rotina da empresa que eu não estou mais capacitado, parece simples mas eu sinto falta disso".

Sobre os treinamentos específicos na área de atuação, $24,4 \%$ dos colaboradores concordam plenamente, 58,5\% concordam e 17,1\% nem concordam nem discordam dessa afirmação. 0 gestor $A$ afirma que na sua unidade há uma instrutora especificamente designada ao treinamento de novos colaboradores, além disso, "quando não há novos, ela treina outros colaboradores que mudam de operação". Registra ainda que os novos colaboradores além de passarem pelo treinamento de integração, posteriormente, no local de trabalho, passam por treinamentos específicos com o acompanhamento dessa instrutora, até se tornarem autônomos no desempenho da atividade. 0 gestor B cita os treinamentos específicos aos colaboradores de sua área, destaca o Plano de Desenvolvimento Individual (PDI) que é elaborado a cada novo colaborador, dependendo da função, da área e do cargo, específico sobre as tarefas a serem executadas.

Cabe destacar que os colaboradores recebem um treinamento prévio a sua entrada na empresa. Em uma parceria entre Instituto Federal de Santa Catarina (IFSC) e a empresa, os futuros colaboradores das unidades produtivas, participam de um curso de costura básica, com carga horária de 80 (oitenta horas). 0 gestor A considera "bem importante esse treinamento, é muito bom, segue um padrão, e aí ele já vem com embasamento".

Os dados relativos a questão o treinamento que recebo é suficiente para o meu aprendizado e desenvolvimento das atividades apontam que $46,3 \%$ dos colaboradores concordam plenamente com a afirmativa, 36,6\% concordam e 17,1\% nem concordam nem discordam. 0 gestor A considera suficiente a carga horária de treinamentos oferecida, em função da instrutora estar em tempo integral e a disposição de preparar os colaboradores para as novas atribuições, também, as líderes de setor acompanham o desempenho na atividade onde a pessoa está alocada. $\mathrm{O}$ gestor $\mathrm{B}$ cita que $\mathrm{O}$ PDI atende à necessidade inicial de um novo colaborador e destaca que nas atividades mais complexas, "o aprendizado vem ao longo da vivência na prática [...] cada coleção é uma etapa de aprendizado [...] é necessário passar por dois ciclos para ter uma vivência completa".

Se 0 treinamento recebido condiz com a realidade da empresa, verifica-se que $65,9 \%$ dos colaboradores concordam plenamente, $26,8 \%$ concordam, 2,4\% nem concordam nem discordam e 4,9\% discordam dessa afirmação. Alguns colaboradores apontaram nas sugestões que os treinamentos poderiam ser mais dinâmicos, mais continuados, com atividades para descontrair, com coisas fáceis de utilizar no dia a dia, com maior aprofundamento dos conteúdos, saber o processo do início ao final.

O gestor A destaca a presença da instrutora de sua unidade, como os treinamentos são elaborados especificamente na prática, para cada operação, e é realizado um acompanhamento personalizado por colaborador, acredita que dessa maneira as capacitações atendam a realidade da empresa. 0 gestor $B$ aponta que os planos de desenvolvimento são elaborados pelos gestores e os instrutores são os próprios colaboradores com mais experiência, que estejam alinhados com os objetivos da empresa.

Questionados se o conhecimento prévio ajudou no desenvolvimento das atividades mais que os treinamentos recebidos, 56,1\% concordam plenamente, 31,7\% concordam, 9,8\% nem concordam nem discordam, 2,4\% discordam. Relatos dos colaboradores durante a resposta a essa pergunta, dizem que a bagagem trazida de outras experiências ajudou no desenvolvimento de suas atividades, mas consideram que os treinamentos da empresa ajudam a entender o negócio e perceber as mudanças que ocorrem durante 0 ano, principalmente quando há momentos de trabalho mais intenso (mostruário e final de coleção). Alguns citam o curso que fizeram no IFSC e que abriu as portas da empresa. Na visão do gestor A, o conhecimento prévio adquirido no curso realizado no IFSC "faz toda a diferença [...] ele já vem embasado, já sabe o que é um tecido, já sabe o que é uma agulha, o que é uma máquina". O gestor B fala que a empresa tenta contratar pessoas que já tenham uma capacitação mínima, pois essa capacitação prévia é fundamental para absorver os 
conhecimentos da empresa. "Nós temos que ser abertos a novas experiências, não dá para contratar pessoas extremamente leigas [...] quanto mais técnico mais a gente exige conhecimento prévio".

A respeito da carga horária dos treinamentos, se é suficiente, para $36,6 \%$ dos respondentes concordam plenamente, outros $36,6 \%$ concordam, $19,5 \%$ dos respondentes que nem concordam nem discordam, 2,4\% discordam e 4,9\% discordam inteiramente. A alegação destacada nas sugestões é que os treinamentos são de curta duração.

Além disso, o gestor A fala que a metodologia aplicada aos treinamentos segue um padrão, é elaborado material conforme a carga horária, que direciona, das operações básicas até as operações específicas de cada célula de trabalho. No que o gestor $B$ vivencia, cita que utiliza o PDI, como modelo padrão, conforme a descrição de cada cargo, a avaliação é realizada conforme a matriz CHA, conhecimento, habilidade e atitude, e o documento é registrado junto ao setor de gestão de pessoas."

Perante as respostas dos colaboradores, é necessário verificar junto ao setor de gestão de pessoas se as avaliações de reação que são aplicadas ao final de cada capacitação, correspondem ao dado levantado. E principalmente, se os colaboradores já vêm relatando que a carga horária está sendo insuficiente, qual(is) alternativa(s) a empresa está adotando no intuito de minimizar essa reação, ou então, de esclarecer o motivo dos horários.

Questionados se os treinamentos recebidos ajudam a melhorar sua avaliação de desempenho e feedback, 58,5\% dos respondentes concordam plenamente, 34,1\% concordam, 7,3\% nem discordam nem concordam. Na opinião do gestor A, os treinamentos ajudam, "com certeza, se eu não tiver colaboradores que venham do treinamento com o IFSC, eu vou ter que ensiná-lo todos aqui, quem já vem com o treinamento anterior, mesmo assim eu continuo com uma programaçáo onde ele vai tendo a evolução diária". O gestor B fala que "junto com a evolução técnica, vem a convivência na empresa, sendo uma etapa importante para 0 novo colaborador, conforme vai tendo esse aprendizado, vai tendo uma sinergia entre os pares".

Os colaboradores julgam importante os treinamentos recebidos, $68,3 \%$ concordam plenamente, $26,8 \%$ concordam e $4,9 \%$ nem concordam nem discordam. O gestor A, afirma "com certeza, que os treinamentos são importantes para o desempenho dos colaboradores". O gestor B corrobora com o gestor A.

Sobre a percepção dos colaboradores quanto ao gestor autorizar a sua liberação para participar dos treinamentos, $61 \%$ concordam plenamente, $24,4 \%$ concordam, $12,2 \%$ nem concordam nem discordam e $4 \%$ discordam dessa afirmativa, isso demonstra que alguns colaboradores percebem a rejeição de seus líderes em liberá-los ao participar dos treinamentos oferecidos, isso também foi destacado em uma das sugestões: "temos dificuldade da participação nos treinamentos". O gestor A alega que faz uma programação junto com a instrutora com base nas datas de entrada dos novos colaboradores, para o treinamento das funções básicas, esse tempo de acompanhamento e adaptação depende de cada colaborador e da operação, isso tudo é feito através de supervisão direta e registro em PDI's (plano de desenvolvimento individual), que vai para a pasta do colaborador no RH (departamento de recursos humanos), sendo uma entrega crítica da gestora, que tem um número pré-definido de horas de treinamento mensalmente. 0 gestor $B$ afirma que é um dos que mais advoga pelos treinamentos "se a gente não treina, eles ficam eternamente dependentes de nós [...] quanto mais eles treinar, melhor pra nós". O gestor B destaca que o colaborador estará apto a "colocar a mão na massa" a partir de desenvolver todo o seu PDI.

Questionados sobre a necessidade de sua participação nos treinamentos, 43,9\% dos colaboradores discordam inteiramente quando questionados se acho desnecessária minha participação nos treinamentos. É necessário averiguar o motivo de 19,5\% concordar inteiramente com a afirmação, 12,2\% concordar, 12,2\% nem concordar nem discordar e $12,2 \%$ discordar, pois estes em algum momento julgam que a sua participação em alguns treinamentos não apresenta relevância.

Além das análises supra apresentadas, o gestor A considera que os treinamentos são primordiais aos colaboradores e expressa a necessidade de focar nos treinamentos anteriores a entrada dos novos, que a parceria com o IFSC deve ser estendida, ampliada pois as pessoas que passam por essa capacitação prévia vem com outro olhar sobre $o$ trabalho, as metas, eficiência produtiva, além disso, cita que seria interessante uma outra pessoa para auxiliar na gestão dos documentos alusivos aos treinamentos, dessa forma direcionar melhor as demandas por tipo de treinamento especificamente a quem mais necessita, desafogando com isso 
o gestor da unidade produtiva. 0 gestor $B$ destaca que no início a carga horária de treinamentos é muito grande com relação à jornada de trabalho, e com o passar do tempo diminui, no entanto é um dos gestores apoiadores dos treinamentos e que prima pelo desenvolvimento de sua equipe, tanto operacional quanto técnica.

\subsection{Discussão}

Com base nas informações levantadas junto aos colaboradores, gestores e setor de gestão de pessoas, percebe-se que há um alinhamento de informações. Como a dinâmica do mundo empresarial remete a constante evolução, no anseio de atender ao que o mercado preconiza, propostas de melhorias são sempre bem-vindas.

Primeiramente, há que se entender se as avaliações de reação das capacitações estão sendo verdadeiramente respondidas e se as sugestões de melhoria, alusivas aos treinamentos, estão sendo aplicadas. Cabe ao setor de gestão de pessoas, deixar claro aos participantes dos treinamentos, a importância de responder, de maneira construtiva, as avaliações de reação. De posse disso, tabular as avaliações de reação, e, na medida do possível, implementar as sugestões. É de fundamental importância que os respondentes percebam que suas contribuições foram postas em prática, caso isso não ocorra, não haverá novas sugestões.

No que se refere a esta pesquisa, sugere-se que as atividades de treinamentos sejam repensadas em tempo disponível, local do treinamento (posto de trabalho, sala específica, IFSC,...). Por mais que haja um roteiro pré-definido, que os instrutores sejam os próprios colaboradores da empresa (em sua maioria), há de se pensar nos preceitos da andragogia, pois, quando a aprendizagem não se revela efetiva, costuma-se atribuir falhas ao professor, ou ao prazo para estudo (SILVA FRANCO et al, 2015).

A unidade Camisaria conta com uma instrutora em tempo integral, que realiza 0 acompanhamento dos colaboradores em novas atividades (operações). Uma proposição com grande potencial de efetividade, é disponibilizar colaboradores que já atuam na empresa, que sejam altamente capacitados de forma técnica e prática, nos processos internos, para realizar esse acompanhamento personalizado, em todas as unidades produtivas. Como relata o gestor $A$, a presença da instrutora é preponderante no desenvolvimento dos colaboradores.

Com essas sugestões, é possível minimizar as discordâncias que se revelaram nas respostas dos colaboradores quanto aos treinamentos específicos na área de atuação, se o treinamento recebido é suficiente, até mesmo se o treinamento condiz com a realidade da empresa. Essas sugestões atenderão principalmente ao quesito carga horária e a necessidade dos colaboradores participar dos treinamentos.

Com relação a percepção dos colaboradores, quanto aos gestores concordarem com sua participação nos treinamentos, é necessário que os próprios gestores deixem claro, a todos os colaboradores, que eles acreditam na importância dos treinamentos para o desenvolvimento da equipe.

\section{CONCLUSÃo}

Considerando que os treinamentos oferecidos aos colaboradores de uma empresa, são fatores de desenvolvimento da organização, a presente pesquisa abordou a efetividade das ações relativas a treinamentos, desenvolvidas pela educação corporativa, nas unidades produtivas de uma indústria têxtil, usando-se de uma abordagem descritiva, tratando os dados de forma qualitativa e quantitativa, assumindo forma de um estudo de caso. Destaca a forma de gestão exercida, o acompanhamento dos gestores de fábrica juntamente com a equipe do setor de gestão de pessoas

Quanto a percepção dos colaboradores frente aos treinamentos desenvolvidos pela empresa em comparação com a percepção dos gestores, as respostas dos colaboradores, se justapõe com o que dizem os gestores. Sobre os principais achados da pesquisa, destaque para o alto índice de afirmações dos respondentes perante aos questionamentos. Percebe-se com isso, que a empresa vem desenvolvendo um trabalho direcionado ao desenvolvimento continuado de seus colaboradores, com planos estruturados, apoiados pela gestão das áreas e o departamento de gestão de pessoas. A contribuição dos colaboradores no que diz 
respeito aos treinamentos oferecidos, mostra que a empresa vem oferecendo capacitação de integração e nas áreas específicas de atuação. Em todos os questionamentos realizados, os colaboradores em sua maioria concordam inteiramente ou concordam com as afirmações.

Mesmo assim, não é unânime a concordância quanto a efetividade dos treinamentos. Colaboradores citam que os treinamentos poderiam ser mais continuados, com atividades diferenciadas, que em alguns momentos os treinamentos poderiam ser aprofundados, com maior carga horária e com atividades práticas. Uma das sugestões que chamam a atenção diz respeito a "saber o processo do início ao final", destarte, melhorias contínuas são sugeridas a empresa.

Na discussão dos achados da pesquisa, sugere-se que o setor responsável pelas avaliações de reação das capacitações, certifiquem-se que estas estão sendo verdadeiramente respondidas e se as sugestões estão sendo acatadas. Outro ponto é promover a diferenciação da abordagem dos treinamentos e que estes sejam revisados em formatos e tempos específicos para cada capacitação.

Conclui-se que a empresa está atuante e a liderança engajada na formação continuada de seu pessoal. De modo geral, a convergência de esforços nos seus processos de educação corporativa vem sendo percebida pela maior parte dos colaboradores e demonstram alinhamento com a gestão estratégica, voltadas ao alcance dos objetivos do negócio, ou seja, o objetivo geral da pesquisa foi atendido, com base nos dados coletados junto aos colaboradores, que estão em sua maioria alinhados com os relatos dos gestores, dessa forma, é possível afirmar que há efetividade nas ações, relativas a treinamentos, desenvolvidas pela educação corporativa, nas unidades produtivas, e estas tem se mostrado eficazes. Dessa maneira, a presente pesquisa demonstra os esforços da empresa em capacitar sua força de trabalho, atendendo um de seus valores que é "reconhecer as competências e valorizar as pessoas em todos os níveis".

Como sugestão de estudos futuros, acrescentar pesquisas a respeito da influência dos treinamentos na produtividade da empresa. Outra sugestão é a de verificar se as ações voltadas a ser uma das melhores empresas para se trabalhar, estão colaborando para diminuir o índice de rotatividade da empresa.

\section{REFERÊNCIAS}

ASSOCIAÇÃO BRASILEIRA DA INDÚSTRIA TÊXTIL E DE CONFECÇÃO. 0 poder da moda: Cenários, Desafios e Perspectivas. Agenda de Competitividade da Indústria Têxtil e de Confecção Brasileira 2015 a 2018. 2015. Disponível em: http://www.abit.org.br/conteudo/links/Poder_moda-cartilhabx.pdf. Acesso em 10 fev. 2017.

ALMEIDA, M. I. R.; TEIXEIRA, M. L. M.; MARTINELLI, D. P. Por que administrar estrategicamente recursos humanos? Revista de Administração de Empresas, v. 33, n. 2, p. 12-24, 1993.

ALPERSTEDT, C. Universidades corporativas: discussão e proposta de uma definição. Revista de Administração Contemporânea, Curitiba, v. 5, n. 3, p. 149 - 165, set./dez. 2001.

ALVES, G. 0 novo (e precário) mundo do trabalho: reestruturação produtiva e crise do sindicalismo. São Paulo: Boitempo Editorial, 2000.

ANDRADE, R. J. F.; RODRIGUES, M. V. R. Educação corporativa: prática de treinamento na sociedade do conhecimento. In: CONGRESSO NACIONAL DE EXCELÊNCIA EM GESTÃO, 4., 2008, Niterói. Anais [...]. NiteróiRJ, 2008.

APPELBAUM, E. et al. Manufacturing competitive advantage: the effects of high performance work systems on plant performance and company outcomes. Manufacturing advantage: Why high-performance work systems pay off. NY: Cornell University Press, 2000.

BARNEY, J. B.; HESTERLY, W. S. Administração e vantagem competitiva. São Paulo: Pearson Prentice Hall, 2007.

BEER, M. et al. Managing human assets: I. a general manager's perspective. Personnel Administrator, 1985. 
BEUREN, I. M. et al. (org.). Como elaborar trabalhos monográficos em contabilidade: teoria e prática. 2. ed. São Paulo: Atlas, 2004.

BOSQUETTI, M. A. Gestão de pessoas, estratégia e performance organizacional: um estudo internacional de casos múltiplos. 2009. 251 p. Tese (Doutorado em Administração) - Universidade de São Paulo, São Paulo, 2009.

BRUNO, F. S. Do mercado interno à globalização: governo, instituições e empresários, planejando o futuro do setor. In: SENAI CETIQT. Globalização da economia têxtil e de confecção brasileira: empresários, governo e academia unidos pelo futuro do setor. Série Desafios para a competitividade: cadeia têxtil, 2007. p. 247-321.

CAON, K. D. et al. Fatores determinantes da evolução da aprendizagem e educação corporativa: de treinamento e desenvolvimento para universidade corporativa. 2007. Tese (Doutorado em Engenharia de Produção) - Universidade Federal de Santa Catarina, Florianópolis, 2007.

CARVALHO, R. P. Universidade corporativa: uma nova estratégia para a aprendizagem organizacional. 2001. Dissertação (Mestrado em Engenharia de Produção), Universidade Federal de Santa Catarina, Florianópolis, 2001.

COLBARI, A. Educação corporativa e desenvolvimento profissional na dinâmica sócio-cultural das empresas. Civitas-Revista de Ciências Sociais, Porto Alegre, v. 7, n. 1, p. 9-34, jan.-jun. 2007.

COSTA, A. C. R.; ROCHA, E. R. P. Panorama da cadeia produtiva têxtil e de confecções e a questão da inovação. BNDES Setorial, Rio de J aneiro, n. 29, p. 159-202, 2009.

DRUCKER, P. F. Sociedade pós-capitalista. São Paulo: Pioneira; São Paulo: Publifolha, 1999.

EBOLI, M. Educação corporativa no Brasil. Mitos e verdades. São Paulo: Gente, 2004.

FIESC, Federação das Indústrias do Estado de Santa Catarina. Santa Catarina em dados: Têxtil \& Confecção / Observatório da Indústria Catarinense. Florianópolis: 2017.

FIGUEIREDO, J. M. et al. Educação corporativa na contemporaneidade: investigações à luz do materialismo histórico dialético. 2016. p. 84. Dissertação (Mestrado em Administração) - Universidade Federal Fluminense, Niterói, 2016.

FLEURY, M. T. L.; FISCHER, R. Gestão de pessoas: os desafios de aproximar a teoria da prática e vice-versa. Revista de Administração, São Paulo v. 33, n. 2, p. 90-94, 1998.

FLEURY, M. T. L. A gestão de competência e a estratégia organizacional. In: Fleury, M. T. L (org.). As pessoas na organização. São Paulo: Editora Gente, 2002, v. 01, p. 51-61.

FRANCO, J. O. Recursos humanos: fundamentos e processos. Curitiba: IESDE BRASIL SA, 2012.

GARAVAN, T. N.; O'CINNEIDE. B. Entrepreneurship education and training programmes: a review and evaluation - part 1. J ournal of European Industrial Training, v. 18, n. 8, p. 3 - 12, 1994.

GARVIN, D. A. Learning in action: a guide to putting the Learning Organization to Work. Massachusetts. Boston: Harvard Business School Press, 2000.

GEREFFI, G.; MEMEDOVIC, O. The global apparel value chain: what prospects for upgrading by developing countries? Vienna: United Nations Industrial Development Organization. 2003.

IBGE. Instituto Brasileiro de Geografia e Estatística. Pesquisa industrial anual 2014 (PIA). Disponível em: http://www.ibge.gov.br/home/.2014. Acesso em: 23 abr. 2017. 
IBGE. Instituto Brasileiro de Geografia e Estatística. Pesquisa industrial mensal de produção física Brasil. Disponível em:

www.ibge.gov.br/Industrias_Extrativas_e_de_Transformacao/Pesquisa_Industrial_Mensal_Producao_Fisica/ Fasciculos/Fasciculo_Indicad̄ores_IBGE_Brasil//pim-pf-br_201608caderno.pdf. 201̄̄. Acessō em: 23 abr. 2017.

IEMI. Brasil Calçados 2013: relatório setorial da indústria de calçados no Brasil. São Paulo: IEMI, 2013.

KAPLAN, R. S.; NORTON, D. P. Mapas estratégicos - Balanced scorecard: convertendo ativos intangíveis em resultados tangíveis. Rio de J aneiro: Elsevier, 2004.

MADRUGA, R. Treinamento e desenvolvimento com foco em educação corporativa. Editora Saraiva, Rio de Janeiro: 2018.

MEISTER, J . C. Educação corporativa: a gestão do capital intelectual através das universidades corporativas. São Paulo: Makron Books, 1999.

MENEGON, Elizangela Maria Pas; POLI, Odilon Luiz; MAZZIONI, Sady. Inovação na indústria do segmento têxtil: um estudo sobre o perfil da produção científica nacional e internacional/Innovation in the textile industry: a study on the profile of national and international scientific production. Brazilian Journal of Development, v. 4, n. 4, p. 1093-1115, 2018.

QUARTIERO, E. M.; BIANCHETTI, L. Educação corporativa. Mundo do trabalho e do conhecimento: aproximações. São Paulo: Cortez, 2005.

RIBEIRO, A. R. S.; MARTINS, P. L.; NETA, M. C. S. Metas organizacionais e gestão estratégica de pessoas: estudo de caso em uma instituição financeira. Revista de Carreiras e Pessoas (ReCaPe). São Paulo. Volume VII Número 02, p. 544 - 563, maio/ago. 2017.

RUAS, R. Desenvolvimento de competências gerenciais e contribuição da aprendizagem organizacional. In: FLEURY, M.T.L.; OLIVEIRA J r., M.M. (org.). Gestão estratégica do conhecimento: integrando aprendizagem, conhecimento e competências. São Paulo: Atlas, 2001. p. 242-269.

SANTOS, A. F. T. Teoria do capital Intelectual e teo ria do capital humano: estado, capital e trabalho na política educacional em dois momentos do processo de acumulação. In: REUNIÃO ANUAL DA ANPED, 27., 2004, Caxambu. Anais da 27a Reunião anual da ANPED, 2004. GT 09 trabalho e educação.

SCHULER, R. S. Strategic human resources management: Linking the people with the strategic needs of the business. Organizational dynamics, v. 21, n. 1, p. 18-32, 1992.

SILVA FRANCO, D. et al. A andragogia na educação corporativa: o caso de uma empresa metalúrgica. Revista de Administração da UNIMEP, Piracicaba, v. 13, n. 2, p. 74 - 99, 2015.

SVEIBY, K. E. A nova riqueza das organizações: gerenciando e avaliando patrimônios de conhecimento. Rio de Janeiro: Campus, 1998.

TACHIZAWA, T. FERREIRA, V. C. P.; FORTUNA, A. A. M. Gestão com pessoas: uma abordagem aplicada às estratégias de negócios. 5. ed. Editora FGV, Rio de Janeiro, 2006.

TARAPANOFF, K. Aprendizado organizacional: panorama da educação corporativa no contexto internacional. In: TARAPANOFF, K. (org.). Inteligência, informação e conhecimento em corporações. Brasília: IBICT, UNESCO, 2006. p. 12-84.

ULRICH, D.; JICK, T.; VON GLINOW, M. Ann. High-impact learning: Building and diffusing learning capability. Organizational dynamics, v. 22, n. 2, p. 52-66, 1993.

VERGARA, S. C. Projetos e relatórios de pesquisa em administração. 16. ed. São Paulo, SP: Atlas, 2016. 
VIANNA, F. L. E. A indústria têxtil e de confecções no Nordeste: características, desafios e oportunidades. Fortaleza: Banco do Nordeste do Brasil, 2005. 